\title{
DIVÓRCIO, RECASAMENTO E A RELAÇÃO ENTRE PADRASTOS E ENTEADOS: REFLEXÕES ENDEREÇADAS AOS TERAPEUTAS DE FAMÍLIA
}

\author{
DIVORCE, REMARRIAGE AND THE RELATIONSHIP BETWEEN STEPFATHERS \\ AND STEPCHILDREN: REFLECTIONS ON THE DYNAMICS OF REMARRIED \\ FAMILIES
}

RESUMO: Com o advento do divórcio, o número de famílias constituídas a partir do recasamento tem crescido significativamente. Padrastos, madrastas e enteados estão cada vez mais presentes no cotidiano familiar. 0 padrasto ainda é visto com ressalvas no meio social, tanto pelos preconceitos existentes, quanto pelas incertezas sobre sua função na dinâmica familiar, especialmente nas situações em que o pai ainda participa ativamente do cotidiano dos filhos. Neste cenário, o que despertou o interesse para a reflexão descrita neste artigo é a dinâmica familiar configurada a partir da inserção do padrasto. A ideia defendida é que a função paterna e a função de padrasto não precisam entrar em conflito, uma vez que podem conviver dialogicamente, sem se sobrepor, cada uma com suas especificidades e em consonância com as características de cada família. 0 presente texto busca problematizar os desafios que o terapeuta de família poderá enfrentar no trabalho com famílias recasadas, com ênfase nas particularidades da função do padrasto nesta dinâmica e buscando refletir de que forma 0 pensamento sistêmico pode colaborar para esse entendimento. Estudos sobre os novos arranjos familiares mostram-se pertinentes, uma vez que o casamento tradicional já deixou de ser a única forma de constituição familiar aceita socialmente.
ABSTRACT: With the advent of divorce, the number of families constituted from remarriage has grown significantly. Stepfathers, stepmothers and stepchildren have become more present in people's daily lives. The stepfather is still seen with reservations in the social environment, both due to the existing prejudices and uncertainties about their role in the family dynamics, especially when the father actively participates in his children's daily life. In this scenario, what aroused the interest for the reflection described in this article is the family dynamics configured by the insertion of the stepfather. The idea defended is that the father and the stepfather can coexist harmoniously, each one with their specificities. The objective of this article is problematize the challenges that the family therapist may face in working with recasted families, with emphasis on the particularities of the stepfather's role and how systemic thinking can contribute to this understanding. Studies on the new family arrangements are relevant, since traditional marriage is no longer the only form of family formation.

KEYWORDS: divorce; remarriage; stepfather; stepchildren; systemic epistemology.

PALAVRAS-CHAVE: divórcio; recasamento; padrasto; enteados; epistemologia sistêmica.

\section{INTRODUÇÃO}

Após o advento do divórcio, definido legalmente como a dissolução definitiva do casamento e que confere às partes o direito de novo casamento civil (IBGE, 2010), um fenômeno que se tornou cada vez mais frequente é a formação de nú-

Recebido em: 06/01/2018 Aprovado em: 30/04/2018
MARCELO RICHAR ARUA PIOVANOTTI

Psicólogo, Secretaria Municipal de Saúde de Florianópolis, SC, Brasil.

\section{DENISE DUQUE}

Coordenadora do Familiare Instituto Sistêmico de Florianópolis, SC, Brasil. 
cleos familiares a partir de um novo casamento. Neste cenário, parece interessante considerar a existência de novos elementos para a compreensão e definição de família.

O número de recasamentos já alcança uma proporção significativa no contexto social em diferentes países do mundo, a exemplo da Alemanha, Canadá e Estados Unidos, nos quais o número de famílias em que pelo menos um dos cônjuges era divorciado ou viúvo no momento da união vem aumentando significativamente. Nos Estados Unidos, por exemplo, o número de recasamentos já alcançou a faixa de $50 \%$ dos casamentos registrados (Soares, 2012).

No Brasil, o número de recasamentos também tem crescido em uma proporção bastante importante. Inúmeros portais on-line de notícias têm divulgado nos últimos anos dados do Instituto Brasileiro de Geografia e Estatística (IBGE) que ilustram essa realidade. De acordo com esses dados, a taxa de recasamento vem crescendo significativamente ao longo dos anos, com registros de $12 \%$ do total das uniões formalizadas em 2001, de 13,7\% em 2004, de $17,6 \%$ em 2009 e de $23,8 \%$ em 2015, um aumento de aproximadamente $98 \%$ em apenas 14 anos.

Assim, com o gradativo aumento dos núcleos familiares constituídos a partir do recasamento, temos como resultado uma ampliação do contexto de relações familiares que ocorrem muito além do espaço da família nuclear, e com características potencialmente diferentes nos diversos núcleos de convivência. As novas rotinas familiares irão envolver pelo menos dois núcleos de moradia em que os filhos terão algum tipo de participação, já que pai e mãe passarão a viver em locais diferentes.

Dentre as implicações desses novos arranjos familiares, a que ainda gera alguma polêmica e muitas incertezas é a presença das funções de padrasto, madrasta e enteados, decorrente da provável e quase inevitável existência de filhos provenientes do relacionamento anterior. Segundo Pasley e Garneau (2016), a presença de filhos de um relacionamento anterior impõe à família recasada um contexto de maior complexidade.

Da mesma forma, torna-se cada vez mais comum a inserção de novas pessoas - até então desconhecidas - na rotina familiar, mas que precisarão ser realocadas nessa dinâmica, e que serão apresentadas como "novos avôs e avós", "novos tios e tias", "novos irmãos e irmãs", e assim por diante, mesmo que ainda não se tenha clareza sobre a nomenclatura dos papéis que passarão a exercer na nova configuração familiar.

Neste cenário de incertezas, ajustes e adaptações, o padrasto ainda costuma ser visto com ressalvas, tanto pelos preconceitos ainda presentes no meio social, quanto pela pouca clareza sobre a sua função na dinâmica familiar, principalmente no que diz respeito às responsabilidades parentais. As dúvidas tendem a ser maiores nas situações em que a figura do pai se faz presente nas rotinas da criança, já que o conceito de padrasto tem em sua origem histórica a noção de substituição da figura paterna. Uma vez que o pai participa da vida de seus filhos, fica mais complexo definir para a figura do padrasto quais seriam as suas funções e responsabilidades junto aos filhos de sua nova companheira.

Assim, uma pergunta que ainda não encontra uma resposta clara é: qual a função parental de um padrasto em um recasamento pós-divórcio, especialmente nas situações em que o pai é participativo? Essa pergunta pode ser de interesse dos terapeutas de família, na medida em que ela tem se 
tornado cada vez mais frequente em seus consultórios e considerando que o conceito de padrasto como substituto da figura paterna já deixou de ser suficiente.

Nesse sentido, o presente texto tem como objetivo problematizar e refletir a respeito das especificidades que o terapeuta de família pode encontrar no trabalho com famílias recasadas, especialmente no que se refere à função do padrasto nesta dinâmica e de que modo o pensamento sistêmico pode colaborar para esse entendimento.

Para embasar a problematização apresentada, os autores fazem uso de autores clássicos do pensamento sistêmico, de modo a exibir uma breve explanação do seu impacto na prática profissional com famílias, em particular no que tange à temática de estudo aqui explorada. Em seguida, apresenta um sucinto histórico das mudanças no código civil brasileiro que tornaram o processo de divórcio mais acessível à população, e como essas reformulações na lei abriram espaço para o recasamento. Oferece, também, com base na literatura pesquisada, reflexões sobre os possíveis desafios que as famílias enfrentarão durante o divórcio e o recasamento, e também sobre os desafios que o terapeuta de família terá diante dos novos arranjos familiares decorrentes desses dois processos. Por último, o texto destaca as particularidades da relação entre padrastos e enteados, problematizando as possíveis consequências dessa relação no contexto familiar.

Estudos sobre os novos arranjos familiares mostram-se pertinentes, pois o casamento tradicional deixou de ser a única forma socialmente aceita de constituição de uma família. O aumento significativo no número de divórcios, o crescente número de recasamentos, a reestruturação nas rotinas parentais, a ampliação do contexto familiar e o grande número de vínculos que se sobrepõem justificam a realização de pesquisas sobre o tema (Cano, Gabarra, Moré, \& Crepaldi, 2009). Os terapeutas de família precisarão estar atentos às novas possibilidades, de modo a evitar a reprodução de velhos preconceitos. Ao ampliarem a reflexão sobre a realidade das famílias, poderão realizar uma prática condizente aos desafios impostos aos novos arranjos familiares (Carter \& McGoldrick, 1995).

\section{O PENSAMENTO SISTÊMICO}

Dentre as inúmeras implicações do pensamento sistêmico na observação dos fenômenos humanos, mudanças significativas no processo de terapia se mostraram inevitáveis, principalmente em termos de sua organização, condução e da postura do terapeuta diante das famílias que o procuram (Anderson \& Goolishian, 1998; Hoffman, 1998; McNamee \& Gergen 1998). Partindo dos pressupostos da complexidade, da instabilidade e da intersubjetividade, com os quais se estabelece uma ênfase na observação de sistemas amplos, contextualizados e que se relacionam em rede, entende-se que o mundo está em constante transformação e em contínua auto-organização (Vasconcellos, 2010).

Nesse sentido, quando se trabalha com famílias e suas relações, busca-se o reconhecimento dos seus contextos de interações, de modo a ampliar a imagem da situação- problema (Grandesso, 2000). A premissa para o terapeuta é de que a família seja vista como um sistema entre tantos outros, sendo essencial para a compreensão de sua dinâmica a constante exploração das relações interpessoais e das normas que regulam o seu funciona- 
mento nos diferentes grupos significativos dos quais faz parte (Andolfi, 1996; Minuchin, 1982).

Um dos pontos do pensamento sistêmico fundamentais para a reflexão descrita neste artigo é o princípio dialógico apresentado por Morin (1982), a partir do qual se considera ser possível articular e unir conceitos costumeiramente vistos como opostos ou antagônicos. Um dos efeitos desse entendimento é compreender que diferentes papéis podem atuar concomitantemente nos contextos familiares, mesmo que tenham a aparência de conflitantes, redundantes ou incompatíveis. Essa compreensão será de suma importância para a reflexão sobre a possibilidade de coexistência harmoniosa das funções de pai e de padrasto.

Nesta perspectiva, postula-se que os conceitos vigentes, a exemplo do conceito de família, variam de acordo com o momento histórico, com os eventos marcantes de um período e em consonância com o padrão cultural de uma época (Capra, 1996; Morin, 1982). Por esse motivo, na abordagem de base sistêmica, parece interessante aos profissionais que atuam na área o devido cuidado para não se fixarem em valores ou padrões de comportamento de uma determinada época, como se estes fossem os únicos modelos de conduta a serem seguidos.

No que se refere às temáticas do divórcio, recasamento e da relação entre padrasto e enteados, os pressupostos do pensamento sistêmico são úteis para a compreensão desses fenômenos e para sua abordagem clínica no contexto de terapia de família, uma vez que a presença da figura do padrasto na dinâmica familiar, assim como o divórcio e o recasamento, ainda são temas que demandam adaptação cultural, trazem consigo uma grande carga de preconceitos e desconhecimento, e ainda geram muitas dúvidas (Cano et al,. 2009; Carter, 1995; Soares, 2012; Valentim de Sousa \& Dias, 2014).

\section{DIVÓRCIO E RECASAMENTO}

A história do divórcio no Brasil começa oficialmente em 1977, com a Emenda Constitucional no 9 , de 28 de junho, que foi regulamentada como lei em 26 de dezembro do mesmo ano, sob o $n^{\circ} 6.515$, e recebeu o nome de a Lei do Divórcio. Inicialmente, a nova lei impunha uma série de critérios burocráticos para definir a dissolução do casamento, instituindo o divórcio tipo conversão, no qual somente após um período obrigatório de três anos de separação judicial é que o casal poderia encerrar definitivamente a conjugalidade, ao requerer sua conversão para divórcio (Freitas, 2013).

A separação judicial, nos termos jurídicos, serviria como um recurso válido para o casal manifestar sua vontade de suspender os deveres conjugais, formalizando as condições de tal suspensão, sem ter que romper definitivamente o vínculo conjugal. Conforme argumenta Silva (2013), no entendimento dos agentes do direito, poderia restar alguma dúvida quanto à dissolução definitiva do casamento, sendo mais adequado aos cônjuges que dissolvessem inicialmente apenas a sociedade conjugal, para, posteriormente, caso tivessem reconsiderado sua decisão, poderem se reconciliar. Nessa época, o divórcio era admitido somente uma única vez.

Contudo, concomitante às modificações históricas no contexto socioeconômico e cultural do Brasil, a Lei do Divórcio sofreu alterações significativas a partir da década de 1980. Com a Constituição Federal de 1988, por exemplo, o prazo para conversão da 
separação judicial em divórcio reduziu de três para um ano e já não havia mais limites no número de divórcios. Outra mudança importante neste processo vem a ocorrer em 2007, com a Lei 11.441, na qual fica definido que o divórcio e a separação consensuais podem ser requeridas por via administrativa. $\mathrm{O}$ casal poderia comparecer a um tabelionato e apresentar o pedido, diminuindo, assim, a burocracia jurídica envolvida no processo. Tinham direito a tal procedimento somente os casais sem filhos menores de idade ou incapazes (Silva, 2013).

A mudança mais recente ocorre a partir da Emenda Constitucional $\mathrm{n}^{\circ}$ 66 de 2010, que acaba com a necessidade da separação judicial prévia para que o divórcio seja concretizado e não impõe restrições em relação à idade dos filhos. A vontade do casal passa a ser a única condição para o pedido de divórcio. Com a simplificação do processo, obtida a partir da nova redação do código civil brasileiro, em 2010, o divórcio se tornou um recurso de fácil acesso a todos aqueles que, independente dos motivos para tal, desejassem encerrar seus casamentos (Silva, 2013).

Dados do Instituto Brasileiro de Geografia e Estatísticas (IBGE) mostram o aumento progressivo no número de divórcios à medida que as alterações no Código Civil foram ocorrendo. Aumento semelhante também aparece no número de casamentos. Para o IBGE, o aumento do número de divórcios e o de casamentos estariam relacionados. As mudanças na legislação que facilitaram a obtenção do divórcio também teriam permitido novas uniões legais, ou a formalização das que já existiam, mas que ainda não haviam sido oficializadas em virtude de impedimentos da lei.

Portanto, o recasamento, impulsionado por alterações do Código Civil, por mudanças socioeconômicas e por transformações culturais do país, aparece no rol dos fenômenos que colaboram para o crescimento da taxa de nupcialidade legal no Brasil. O casamento ainda se apresenta como uma instituição valorizada no contexto social, ao ponto de muitos casais optarem pelo divórcio justamente por acreditarem que o casamento possa ser mais do que os seus relacionamentos atuais. Diante de uma relação conjugal aquém das expectativas do casal, o divórcio seria uma estratégia válida na busca por relacionamentos mais satisfatórios (Bernardi, Dias, Machado, Nonato \& Féres-Carneiro, 2016; Cartwright \& Gibson, 2013; Silva, Trindade, \& Silva, 2012).

O divórcio e o recasamento já fazem parte da realidade brasileira em uma proporção significativa, em todos os seguimentos da sociedade. Nesse sentido, evidencia-se mais uma vez a importância de ampliar a compreensão de seus impactos nas rotinas familiares, de modo a oferecer uma melhor abordagem do tema e um leque maior de opções para o enfrentamento dessas questões durante o ciclo de vida familiar.

\section{QUESTÕES PARA TERAPIA FAMILIAR SISTÊMICA NO PROCESSO DE DIVÓRCIO E RECASAMENTO}

Os estudos na área de família ressaltam que o divórcio é um processo complexo, pluridimensional e que ocorre de forma diferenciada em cada família (Cano et al., 2009). O grau do impacto que a família sofrerá depende, entre outros fatores, da fase do ciclo de vida que a família estiver vivendo no momento do divórcio e de questões relacionadas ao contexto, uma vez que o divórcio aumenta significativamente a complexidade das tarefas desenvol-

\section{(1)}


vimentais que deverão ser enfrentadas naquela e também nas fases seguintes do ciclo de vida familiar (Carter \& McGoldrick, 1995).

Portanto, é prudente que os terapeutas de família estejam atentos ao fato de que os membros da família estão emocionalmente em risco diante do divórcio, pois precisarão lidar com o enfrentamento de eventos que são, inevitavelmente, fonte de ansiedade e angústia, tais como o período de tomada de decisão, o anúncio da decisão para o restante da família e amigos, a separação concreta, as discussões a respeito das finanças e dos filhos, possíveis consultas com advogados e, finalmente, a redefinição para uma nova vida (Carter \& McGoldrick, 1995).

Nesse sentido, o divórcio é visto como uma crise que cria um estado de desequilíbrio para todas as pessoas envolvidas, em todos os níveis geracionais e por todo o sistema familiar (Cano et al., 2009). A família que passa pelo processo de divórcio apresenta questões complexas para as quais não existem soluções simples. O conflito vivenciado pelo casal responde a questões enraizadas na história de cada indivíduo e que não são compensadas apenas pela separação física. O divórcio demanda ajustes pessoais tanto em níveis emocionais, quanto em questões práticas do cotidiano. O divórcio se configura, portanto, como um potencializador de conflitos emocionais, que devem ser reconhecidos e considerados no processo de terapia (Cano et al., 2009; Saccu \& Montinari, 1995).

Segundo Soares (2012), após o divórcio, os filhos passam a ter um papel central no contexto familiar, pois é em torno deles que o casal recém desfeito precisará manter algum contato, mesmo que a conjugalidade tenha sido rompida. As mudanças costumam vir acompanhadas por um intrinca- do conjunto de sentimentos, que podem incluir a solidão, a angústia e o medo do abandono, principalmente nas situações em que pais e filhos não conversam a respeito da separação (Saccu \& Montinari, 1995; Wallerstein \& Kelly, 1998; Wallerstein, Lewis, \& Blakeslee, 2002).

Os filhos irão vivenciar momentos de tensão e sofrimento durante o divórcio de seus pais. Diante da frustração de expectativas comuns ao enlace matrimonial e das mudanças significativas na rotina familiar que surgem em decorrência do divórcio, acaba sendo um tanto quanto inevitável que os filhos acompanhem ou enfrentem algum tipo de sofrimento, seja como espectadores da dor do outro ou como aqueles que a sentem diretamente. Nesse sentido, o processo de terapia pode ter um papel importante para a dinâmica familiar, colaborando para a abertura de canais claros de comunicação, de modo a evitar, principalmente nos filhos pequenos, fantasias ou culpabilizações desnecessárias.

Apesar das dificuldades inerentes ao processo de divórcio, na maioria das vezes, ele se apresenta como uma situação inevitável e desejada, em virtude da amplitude dos problemas vividos pelo casal (Travis, 2003). O processo de divórcio tem o potencial de aumentar as dificuldades, mas também o de estimular o crescimento pessoal de uma maneira que não era possível anteriormente. A carga emocional decorrente do divórcio, tanto negativa quanto positiva, resulta em mudanças importantes na maneira como cada pessoa se percebe e se coloca no mundo, sendo este, talvez, um dos principais motivos da ambivalência inerente ao processo (Saccu \& Montinari, 1995).

Nesse sentido, parece interessante que os terapeutas de família estejam 
abertos a compreender o divórcio de modo abrangente, considerando as diferentes possibilidades do sistema, tanto em termos das dificuldades, por um lado, quanto dos recursos, por outro. Cano et al. (2009) apontam que, com o passar do tempo, o divórcio pode ser benéfico para os membros da família, que passam a perceber uma melhora na qualidade de vida, tanto a dos ex-cônjuges como a dos filhos, contribuindo, assim, para a resiliência e para o amadurecimento emocional de todos os envolvidos.

Um exemplo dessa situação é a pesquisa realizada por Souza (2000) com adolescentes que vivenciaram a separação dos pais durante a infância. A partir dos dados coletados, evidenciou-se que os adolescentes pesquisados concluíram que a separação de seus pais foi uma solução adequada para os conflitos do casal e da família, mesmo que inicialmente tenham prevalecido sentimentos negativos. Resultado semelhante foi encontrado por Valentim de Sousa e Dias (2014), em recente pesquisa com famílias recasadas, na qual os participantes referiram um número significativamente maior de aspectos positivos na nova configuração familiar, mesmo que tenham experimentado algumas dificuldades após o divórcio de seus pais.

Para o casal que se divorcia, a formação de um novo relacionamento apresenta importantes desafios ao sistema familiar, uma vez que vem acompanhada de expectativas de recuperação da autoestima e de vivências positivas que não puderam ser plenamente alcançadas no relacionamento anterior (Carter \& McGoldrick, 1995). O recasamento, a exemplo do divórcio, altera a estrutura e a dinâmica familiar como um todo, à medida que modifica formas de conduta, relações parentais, espaços de convivência, além de romper com os modelos tradicionais de família vigentes na sociedade. A família recasada passará por um período de intensas reestruturações, mediante a integração e inserção de novos elementos no contexto de convivência do sistema familiar.

Soares (2012) apresenta uma contribuição importante para o debate desse tema, ao destacar duas das principais dificuldades encontradas pelas famílias recasadas. A primeira consiste na dificuldade de encontrar uma nomenclatura que identifique com clareza os integrantes do novo sistema e que evidencie seus vínculos, uma vez que ainda prevalece como legítima a imagem da tradicional configuração pai, mãe e filhos. A segunda diz respeito à dificuldade das pessoas em responder quem faz parte de sua família, diante da incerteza a respeito de quais critérios devem ser utilizados para responder a essa pergunta.

Da mesma forma, o estudo de Travis (2003), cujo objetivo era o de verificar as percepções de terapeutas de família a respeito do recasamento, mostrou que esses profissionais também apresentam dificuldade semelhante ao definir o que é família e quem faz parte dela. Tal dificuldade foi atribuída à presença de múltiplos modelos com os quais os profissionais precisam lidar em sua prática cotidiana. De alguma forma, a multiplicidade de arranjos familiares e as diferentes formas de interação dentro desses sistemas a partir do recasamento geraram uma crise conceitual em torno desse fenômeno.

A esse respeito, Martins, McNamee e Guanaes-Lorenzi (2015) apresentam, a partir de uma perspectiva construcionista, contribuições importantes do que seja a família. Os autores argumentam que a família se configura enquanto uma realização discursivamente produzida e em constante processo de$$
\text { nise Duque }
$$

$$
\text { (2) }
$$


construção, a partir das interações sociais existentes. Este intercâmbio social se configura enquanto o espaço privilegiado no qual as pessoas negociam, estabelecem e legitimam um conceito que defina o mundo que as cerca. Nesse sentido, na tentativa de alcançar alguma definição capaz de explicar, mesmo que minimamente, o que é o sistema familiar, se recorre a "vocabulários socialmente produzidos, situados em tempos históricos específicos e que permitem produzir versões do que uma família pode ser" (p. 17).

De acordo com Martins, McNamee e Guanaes-Lorenzi (2015), a principal implicação para os terapeutas ao adotarem uma concepção discursiva de família é a possibilidade de manter uma postura aberta, que permita entender as diferentes formas como as pessoas descrevem suas conexões com os demais integrantes de seu contexto de interações e de que forma esses relacionamentos funcionam em seu cotidiano. Ao perceber a família por uma ótica construcionista, o terapeuta assumiria uma postura de genuína curiosidade, que o auxiliará a compreender de que forma as pessoas atribuem sentidos ao contexto familiar e às funções que cada um ocupa nesse sistema. Portanto, durante o processo conversacional que se desenrola no atendimento familiar, a conversa terapêutica se estabelece enquanto um contexto de produção de sentidos, no qual poderão ser construídas diferentes versões do que seja a família e de qual função cada integrante deve exercer.

Nesse sentido, o divórcio e o recasamento direcionam os profissionais da área a ampliar sua compreensão sobre o sistema familiar, a partir da inclusão de outros fatores que não estavam presentes no primeiro relacionamento. Também é necessário considerar que $\theta$ a nova configuração da família potencializa as dúvidas e aumenta a necessidade de ajustes comuns a todo enlace afetivo. Dentre as questões a serem elaboradas e ajustadas entre as famílias que estão se unindo mediante recasamento, Carter e McGoldrick (1995) salientam que as conflitivas referentes ao casamento anterior e ao processo de divórcio são as de maior repercussão.

Outro ponto que vale destacar e que tem forte impacto na organização das novas rotinas familiares após o divórcio é a guarda dos filhos. No Brasil, a partir de 22 de dezembro de 2014, passou a prevalecer a lei que define a regra da guarda compartilhada em casos de divórcio. A nova regra tem como prerrogativa que a divisão do tempo de convivência dos filhos seja equilibrada com cada um dos pais, exceto em situações específicas, como quando um dos pais abre mão da guarda voluntariamente ou o juiz entende que uma das partes não apresenta os requisitos mínimos para o cuidado de uma criança.

No entendimento de Levy (2009), os agentes do direito favoráveis à guarda compartilhada entendem que o envolvimento de ambos os genitores na criação dos filhos amenizaria os sentimentos negativos decorrentes da separação conjugal. A premissa básica é de que os pais cooperem entre si, mesmo separados, de modo a não expor os filhos a seus conflitos, minimizando possíveis desajustes e diminuindo a probabilidade de desenvolverem problemas emocionais, escolares e sociais.

Apesar das possíveis críticas à lei da guarda compartilhada, ela se apresenta ao contexto social como uma nova realidade que precisa ser considerada quando se pensa na estruturação da dinâmica familiar. Com a formação de dois núcleos diferentes de moradia, a casa do pai e a casa da mãe, os filhos 
terão que enfrentar um processo de adaptação a pelo menos dois conjuntos diferentes de regras de convivência doméstica, principalmente se houver uma diferença significativa entre os estilos de vida do pai e da mãe.

De todo modo, mesmo diante dos riscos, das ambivalências e polêmicas inerentes ao processo, as famílias recasadas podem oferecer um exemplo interessante de união familiar e de novos valores aos jovens. De modo geral, os filhos têm demonstrado capacidade de aceitar as diferentes modalidades de união conjugal e de conceber a família a partir de critérios variados, indicando que as múltiplas possibilidades de rearranjos familiares são válidas e podem ser produtivas (Cano et al., 2009; Souza \& Ramires, 2006; Valentim de Sousa \& Dias, 2014).

Independente da configuração, a família se estrutura enquanto um espaço de experiências e emoções intensas, determinantes para os seres humanos, tanto em aspectos positivos, quanto negativos (Wagner, 2002). Segundo Oliveira, Siqueira, Dell'Aglio e Lopes (2008), o bem-estar da criança não estaria associado ao fato dela conviver na mesma residência com outro par parental (padrasto ou madrasta); o que predomina como fator determinante para o bem-estar dos filhos e da família é o desempenho dos papéis, das funções e a qualidade das relações existentes entre seus membros.

Nesse sentido, fica evidente a necessidade dos terapeutas de família estarem atentos às questões intrínsecas aos conflitos emocionais que potencialmente irão surgir em todos os envolvidos; de modo a considerar a complexidade de todo o processo, que começa com a decisão de divorciar-se, passa pelo momento de estabelecer um núcleo familiar diferente do anterior, e segue pela definição das novas funções e papéis que serão assumidos diante da nova configuração da família.

Vale salientar que há uma série de tarefas desenvolvimentais relativamente estáveis a serem enfrentadas em cada uma das etapas do ciclo familiar, e que podem apresentar resultados positivos para todos, caso sejam esclarecidas e trabalhadas a contento (Carter \& McGoldrick, 1995). O processo terapêutico se mostra importante na adaptação ao novo estilo de vida, principalmente nos casos em que a resolução das perdas inerentes ao divórcio não foram suficientemente elaboradas (Souza, 2000).

Por esse motivo, os profissionais acabam se vendo no lugar de repensar suas práticas, seu modo de entender a conjugalidade e o próprio conceito de família. A perspectiva dialógica se mostra como uma estratégia interessante para lidar com este impasse, uma vez que destaca a possibilidade de múltiplos padrões e configurações familiares compartilharem o mesmo momento histórico, sem necessariamente entrarem em conflito conceitual. Afinal, a família contemporânea já não comporta mais apenas uma única definição (Féres-Carneiro, 2005; Gergen \& Davis, 1997).

\section{A RELAÇÃO ENTRE PADRASTO E ENTEADO}

Conforme apontado por Soares (2012), no recasamento, há duas formas básicas para uma família com padrasto e madrasta se constituir: a viuvez e o divórcio. Nas situações de viuvez, o padrasto e a madrasta ocupariam um lugar no contexto familiar a partir da ausência definitiva de um dos genitores, em substituição, até certo ponto, da figura parental que não está mais presente. No divórcio, 
por outro lado, a figura parental biológica, mesmo que em maior ou menor grau, está potencialmente presente na vida da família.

Historicamente, a figura do padrasto se fazia presente quase que exclusivamente nas situações de viuvez. As dissoluções do casamento eram incomuns em outras épocas, principalmente por questões pertinentes ao estigma social e à tradição religiosa. Conforme a tradição católica, por exemplo, "o que Deus une, o homem não separa” (Marcos 10:9, Bíblia Sagrada). O termo padrasto remete, portanto, à época em que a figura do padrasto entrava na família basicamente em substituição à figura paterna, tornando-se a nova referência masculina do lar (Soares 2009).

A ideia de padrasto como substituto do pai parece estar relacionada à idealização do modelo de família nuclear e aos papéis ainda atribuídos ao homem no contexto social (Alves \& Arpin, 2017; Valentim de Souza \& Dias, 2014). As famílias recasadas tendem a se basear no modelo da família nuclear intacta, por ainda entenderem que o modelo tradicional é o mais adequado socialmente (Guimarães \& Amaral, 2009; Saraiva, Levy, \& Magalhães, 2014). Contudo, nas famílias recasadas pós-divórcio, a ideia de substituição da figura paterna já não faz tanto sentido, uma vez que o pai ainda está potencialmente presente na vida dos filhos.

Segundo Soares (2012), a noção substitutiva em torno do termo padrasto teria o potencial de intensificar conflitos latentes entre os genitores, típicos do processo de divórcio, especialmente no que tange à figura paterna, que pode sentir seu lugar perante os filhos ameaçado, ainda mais nas situações em que os filhos venham a se conectar afetivamente ao padrasto.
Conflitos de lealdade podem surgir a esse respeito, uma vez que os filhos podem se sentir divididos entre a figura paterna e o padrasto, ao nutrirem sentimentos positivos pelos dois (Rocha, 2015).

A construção de um relacionamento afetivo com os enteados não é uma tarefa fácil (Saraiva, 2013). O novo relacionamento amoroso da mãe indica para os filhos, por exemplo, que a separação dos pais tende a ser definitiva, o que pode resultar em conflitos entre padrasto e enteados (Carter \& McGoldrick, 1995; Rocha, 2015; Soares, 2012). O padrasto também carrega o peso de um mito social. Sobre ele recai a desconfiança da representação da figura do abusador, que inevitavelmente irá maltratar os enteados (Soares, 2009; Valentim de Sousa \& Dias, 2014; Wagner, 2002). Prevalece a ideia de que somente os pais, sob a égide do vínculo biológico, seriam capazes de cuidar adequadamente das crianças.

Contudo, dados de pesquisas recentes, a exemplo de Trindade et al. (2014) e Serafim et al. (2011), mostram que o padrasto não é o principal agente de violência contra as crianças, e que não há diferenças significativas entre o índice de abuso perpetrado por pais e padrastos. Nesse sentido, o abuso infantil, seja ele sexual ou de outra ordem, se caracteriza como uma prática de abusadores, independente do vínculo que tenham com a criança. O abuso infantil responde a uma condição psicológica do abusador e não ao fato de ocupar o lugar de padrasto, ou qualquer outro, na dinâmica familiar.

Outros dados demonstram que padrastos podem desempenhar de forma exitosa o papel parental, independente do vínculo sanguíneo. Wagner, Ribeiro, Arteche e Bornholdt (1999), por exemplo, em sua pesquisa sobre 
o bem-estar de adolescentes em famílias recasadas, encontraram dados consistentes demonstrando que dos 149 adolescentes que vivem com seus padrastos, $125(83,9 \%)$ possuem um nível de bem-estar entre muito bom e bom, não havendo diferença significativa entre os adolescentes de famílias de primeiro casamento e famílias recasadas. $\mathrm{O}$ fator prevalecente para $\mathrm{o}$ bem-estar dos adolescentes nas famílias estudadas foi a dinâmica relacional familiar, e não a sua configuração.

Os conflitos entre padrasto e enteados acabam recebendo maior destaque no contexto social, provavelmente, por ainda haver uma relativa estranheza e desconhecimento sobre a configuração das famílias recasadas, mesmo que ela venha ocupando cada vez mais espaço na sociedade. Por outro lado, os conflitos entre pai e filhos, inerentes ao contexto da família tradicional, acabam sendo banalizados por fazerem parte do cotidiano das pessoas há muitas gerações e já terem entrado na categoria da normalidade.

Ainda é comum ouvir pessoas comentando que os filhos de casais separados e que convivem com padrastos e madrastas serão inevitavelmente problemáticos. Costuma prevalecer a concepção de que são crianças em profundo sofrimento, perturbadas pelo processo que viveram e que possivelmente ainda vivem (Travis, 2003). Muitas vezes, o padrasto acaba sendo culpabilizado por esses problemas, por ser visto como um potencial perpetrador de maus tratos e negligência para com os filhos de sua esposa.

No entanto, já há na literatura de família um conjunto consistente de informações e dados, a exemplo dos que já foram referidos neste texto, demonstrando que a chegada de um novo membro parental e a consequente estruturação de uma nova dinâmica familiar decorrente do recasamento podem gerar sentimentos positivos com o passar do tempo. Caso o novo casamento seja minimamente harmonioso e gere satisfação, os filhos começam a perceber que seus pais estão mais felizes, tranquilos e que seu relacionamento com eles melhorou, o que possibilita o sentimento de pertencimento a uma família completa novamente (Cano et al., 2009; Ferraris, 2002; Valentim de Sousa \& Dias, 2014).

Outro ponto da relação entre padrasto e enteados a ser observado diz respeito especificamente aos casos em que o pai participa ativamente da rotina dos filhos. Diante da necessidade de ampliar e relativizar o conceito de família, o papel atribuído ao padrasto também deve ser repensado. Mais do que a superação dos preconceitos ainda vigentes no contexto social, também caberia ao terapeuta de família abrir espaço para a reflexão junto às famílias sobre qual função será conferida ao padrasto e que expectativas recairão sobre ele. Apesar de parecer uma obviedade, essa questão traz consigo uma sutileza que merece ser observada.

Costumeiramente, as pessoas dizem que o bom padrasto é aquele que ocupa o lugar de "outro pai”. Frases populares como "cuida tão bem que até parece um pai", "ele é um homem muito bom, é um pai para os filhos dela" ou "Deus é pai, não é padrasto" indicam uma clara oposição entre as figuras do pai naturalmente bom, por um lado, e do padrasto inevitavelmente mau, por outro. A sutileza desse discurso social já não está mais na necessidade de superação dos preconceitos em torno do homem que casou com uma mulher com filhos - a sociedade até se mostra capaz de reconhecer que esse homem seja bom, mas na 
ideia de que ele precise ocupar o lugar de pai. No ideário popular, parece que somente seria possível a construção de um vínculo positivo com seus enteados, se o padrasto ocupasse um lugar que não é seu.

Os terapeutas de família que não estiverem atentos a essa questão e que compartilharem dessa crença correrão o risco de assumirem a postura de trabalhar com pais e padrastos de modo a conduzi-los a aceitar que as crianças ganharam um novo pai. Os riscos desse modo de pensar recaem sobre o pai, a criança e o padrasto. O homem que acompanhou a gestação e o nascimento, concedeu o primeiro colo, acompanhou os primeiros passos e viveu o processo inicial de construção de vínculo com aquele pequeno ser, pode entender que seu lugar de pai está ameaçado, apenas por ter deixado de ser marido da mãe de seus filhos. Também pode passar a criar fantasias de que as pessoas o consideram um pai falho, ausente, incapaz, incompleto e ultrapassado, que precisaria ter seus erros compensados por um novo homem.

Podem ocorrer situações, inclusive, em que esse discurso venha a ser reforçado por mães que ainda vivem as mágoas inerentes ao processo de divórcio. A criança, por sua vez, poderá ser colocada em uma posição desfavorável, por ter que lidar com ciúmes, disputas e ambivalências em torno do seu amor. O padrasto corre o risco se ver apenas como um pai substituto, de segunda grandeza, de importância marginal e incapaz de desempenhar a contento a função que lhe for atribuída.

Nesse sentido, colocar sobre a relação padrasto e enteados expectativas afetivas e comportamentais análogas às colocadas sobre a relação pai e filhos pode se configurar como mais um peso para os envolvidos. Apa- rentemente, essas expectativas não teriam como ser alcançadas, pois, de modo geral, quando o padrasto chega à família, a história de vinculação inicial com a figura parental masculina já ocorreu, deixou marcas que não poderão ser apagadas e quem fez parte dela ainda está presente no cotidiano da criança.

O processo de inserção do padrasto na vida de seus enteados e a história de formação desse vínculo talvez precisem ser entendidas por outra ótica. Afinal, pai e padrasto ocupam lugares diferentes no tempo e no espaço da família. $\mathrm{O}$ vínculo entre padrasto e enteados é de outra ordem, com uma história específica e não tem paralelo com a história vivida entre a criança e seu pai. Pode-se dizer que sendo o script diferente, o desenrolar da história também o será, demandando posturas e posicionamentos específicos para cada ocasião e contexto.

Novos questionamentos precisam ser considerados no processo de terapia a partir dessa reflexão. O terapeuta também poderia se fazer perguntas como:

Vale a pena atribuir tanto ao pai quanto ao padrasto a mesma função e correr o risco de fomentar a disputa de quem é o melhor? A função do padrasto está clara para o sistema familiar? A presença do padrasto teria outra função, ainda pouco conhecida, mas que também poderia ser importante para o desenvolvimento das crianças e das relações familiares? Atribuir ao padrasto o status de "pai" responde aos preconceitos arraigados na sociedade de que o padrasto é mau, enquanto o pai é indiscutivelmente bom? O padrasto é "complementar" ou vê-lo dessa forma dá a entender que ele precisa compensar um pai supostamente 
ausente? O pai está mesmo em falta ou, no momento, isso é tudo o que ele pode oferecer?

e as provavelmente mais importantes,

Pai e padrasto precisam ocupar o mesmo papel, ou podem cada um ter uma função com características próprias, já que os lugares que ocupam na história da criança e da família são, inevitavelmente, diferentes? Pai e padrasto podem legitimar um o papel do outro junto às crianças, de modo a diminuir a possibilidade de elas criarem fantasias de que devem se posicionar a favor de um e contra o outro?

Aparentemente, esses questionamentos, ainda com respostas em construção, aumentariam a possibilidade de um entendimento sobre a dinâmica familiar que preserve e assegure o lugar de cada um de seus integrantes, minimizando as possíveis disputas entre pai e padrasto. Parece prudente que o lugar do pai seja preservado, assim como o de padrasto, justamente para que não sejam vistos como rivais em constante batalha. Desse modo, as crianças encontrariam a tranquilidade para se vincular, sem o receio de ferir os sentimentos de um ou de outro.

Ainda sobre essa questão, a reflexão a respeito da possibilidade de o padrasto ser visto como um integrante do sistema familiar com particularidades e atribuições próprias, que demandam um processo de construção e compreensão, sem precisar ocupar o lugar de pai, traz consigo a necessidade de também questionar as crenças existentes em torno da figura paterna. Parece apropriado evitar a naturalização da função paterna, já que as práticas parentais e o conceito de paterni- dade também se configuram enquanto constantes construções no contexto social. Afinal, a história mostra que vinculação biológica não é, nunca foi e dificilmente será garantia de bons cuidados e de afetos positivos.

\section{CONSIDERAÇÕES FINAIS}

O estudo a respeito do divórcio, do recasamento e da relação entre padrasto e enteados se configura como um campo abrangente e fascinante, justamente por se tratar de questões ainda recentes e de difícil compreensão no momento histórico em que vivemos. A infinidade de variáveis envolvidas nesse processo reflete a complexidade inerente às diferentes possibilidades de configuração familiar que surgem a partir do divórcio e do recasamento.

O terapeuta de família se vê convidado a ampliar seu foco de observação a respeito dos fenômenos relacionais que surgem no contexto familiar e a rever conceitos sobre o que é família. Diante dessa realidade, considerando que o conceito de família já deixou de ter como parâmetros definidores apenas a clássica consanguinidade e a tradicional coabitação, também parece interessante repensar o setting terapêutico de modo a comportar os outros integrantes que passam a compor o sistema familiar.

Seguindo com a ideia de novos questionamentos que devem acompanhar o terapeuta em sua prática, surgem perguntas a respeito do processo terapêutico e de como ele deve ser organizado, tais como:

Quem deveria ser convidado a participar das consultas? Poderiam pai, mãe, madrasta e padrasto ocuparem seus assentos no consultório do 
terapeuta, na presença de seus filhos/ enteados, para debaterem os assuntos pertinentes à família? Quais recursos o terapeuta de família precisará utilizar e desenvolver para fomentar conversações e lidar com o enfrentamento de possíveis conflitos que irão surgir nesse sistema, tais como ciúmes, disputas de poder e mágoas latentes? Quem deveria participar da discussão referente à escola, às regras de comportamento, às finanças e à idade certa para começar a namorar? Como ajudar as famílias a definirem os direitos e deveres atribuídos a cada integrante do sistema? Quais os limites da autoridade do padrasto sobre os enteados? Como obter a cooperação de todos os envolvidos nessa dinâmica, de modo a construírem em conjunto estratégias para lidar com as dificuldades esperadas em cada fase do ciclo de vida familiar? Como compreender os ciclos de vida familiar mediante a presença dos novos integrantes da família e novas formas de se relacionar com eles?

entre tantas outras que, inevitavelmente, passarão a ser cada vez mais frequentes na prática dos profissionais que recebem essas famílias em seus consultórios.

Talvez, um primeiro passo para encontrar as respostas para esses questionamentos passe pelo investimento em novas pesquisas a respeito desses fenômenos e por relatos de experiências de intervenção terapêutica que possam ampliar o debate sobre o tema. A disseminação dessas novas configurações precisa estar representada de maneira clara e ampliada, ao ponto de colaborar com a estruturação dos relacionamentos interpessoais, uma vez que o divórcio e o recasamento são realidades cada vez mais presentes nos diferentes segmentos da sociedade brasileira.
O segundo passo, e talvez o mais importante, seja a ampliação da compreensão sobre o que seja a família. Ao compreender que a família é um fenômeno em processo constante de construção e transformação, que precisa ser entendida de acordo com a amplitude das relações estabelecidas nos inúmeros contextos em que se insere e da complexidade subjetiva que mantém seus integrantes conectados, o terapeuta de família poderá ter incursões produtivas nesse sistema, de modo a colaborar para o seu desenvolvimento como um todo. Dessa forma, as famílias que passaram pelos processos de divórcio e recasamento, e que hoje contam com a presença das funções de padrasto, madrasta e enteados, poderão receber a atenção necessária em suas dificuldades cotidianas da dinâmica familiar.

Os terapeutas de família serão convidados a participar intensamente desse processo, emprestando seus conhecimentos técnicos para orientar as famílias que os procuram na reestruturação de suas rotinas familiares. Para poderem realizar a contento seu trabalho, parece interessante terem em mente que pode ser necessário revisitar suas próprias convicções e concepções do que seja a família, despindo-se de preconceitos e aceitando a diversidade de possibilidades de vinculação familiar que se impõe na atualidade.

\section{REFERÊNCIAS}

Alves, A. P. \& Arpin, D. M. (2017). Conjugalidade e os conflitos vivenciados. Pensando famílias, 21(1), 3-19. Anderson, H. \& Goolishian, H. (1998). O cliente é o especialista: uma abordagem para a terapia a partir de uma posição do não-saber. In $\mathrm{S}$. $\mathrm{McNa}$ - 
mee \& K. Gergen (Orgs.), Terapia como construção social (pp. 34-49). Porto Alegre: Artes Médicas.

Andolfi, M. (1996). A linguagem do encontro terapêutico. Porto Alegre: Artes Médicas.

Bernardi, D., Dias, M. Vu, Machado, R. N, \& Féres-Carneiro, T. (2016). Definindo fronteiras no recasamento: relato de uma experiência clínica. Pensando familias, 20(2), 43-55. Recuperado de http://pepsic.bvsalud.org/scielo.php? script $=$ sci_ arttext\&pid=S1679-494X20160002 $00004 \& \operatorname{lng}=p t \& t \operatorname{lng}=p t$

Cano, D. S., Gabarra, L. M.s Moré, C. 0., \& Crepaldi, M. A. (2009) As transições familiares do divórcio ao recasamento no contexto brasileiro. Psicologia: Reflexão e Crítica, 22(2), 214-222.

Capra, F. (1996). A teia da vida: uma nova compreensão científica dos sistemas vivos. São Paulo: Cultrix.

Carter, B. \& McGoldrick, M. (1995). As mudanças no ciclo de vida familiar: uma estrutura para a terapia familiar (2a ed.). Porto Alegre: Artes Médicas.

Carter, E. (1995). Famílias reconstituídas: a criação de um novo paradigma. In M. Andolfi, C. Angelo, \& C. Saccu (Orgs.), O casal em crise (pp. 193-198). São Paulo: Summus.

Cartwright, C. \& Gibson, K. (2013). The effects of co-parenting relationships with ex-spouses on couples in step-families. Family Matters, 92, 18-28.

Féres-Carneirro, T. (2005). Entrevista Familiar Estruturada - EFE: um método clínico de avaliação das relações familiares. São Paulo: Casa do Psicólogo.

Ferraris, A. O. (2002). Filhos de famílias divorciadas e reconstituídas: identidade e história familiar. In M. Andolfi (Org.), A crise do casal: uma perspectiva sistêmico-relacional (pp. 249-263). Porto Alegre: Artmed.
Freitas, N. 0. A. (2013). O novo divórcio e o Estatuto das Famílias. Revista Jus Navigandi, 18(3575), 1-4. Recuperado de http://jus.com.br/ artigos/24193

Gergen, M. M., \& Davis, S. N. (1997). Toward a new psychology of gender: opening conversations. In Toward a new psychology of gender: a reader (pp. 1-27). New York: Routledge.

Guimarães, N. V. 0. \& Amaral, A. C. (2009). Famílias com filhos de casamentos anteriores. In L. C. Osório \& M. E. P. Valle (Orgs.), Manual de terapia familiar (pp. 273-285). Porto Alegre: Artmed.

Grandesso, M. A. (2000), Sobre a reconstrução do significado: uma análise epistemológica e hermenêutica da prática clínica. São Paulo: Casa do Psicólogo.

Hoffman, L. (1998). Setting aside the model in family therapy. Journal of Marital \& Family Therapy. 24, 145-156.

Instituto Brasileiro de Geografia e Estatística - IBGE: (2010). Estatísticas do Registro Civil, 37, 1-178.

Levy, L. A. C. (2009). O estudo sobre a guarda compartilhada. Âmbito Jurídico, Rio Grande, XII, n. 66. Recuperado de http://www. ambito-juridico.com.br/site/ind ex.php?n_link=revista_artigos_ leitura\&artigo_id $=6416$

Martins, P. P. S., McNamee, S., \& Guanaes-Lorenzi, C. (2015). Família como realização discursiva: uma explicação relacional. Nova Perspectiva Sistêmica, 52, 9-24. Recuperado de http://www.revistanps.com.br/index.php/nps/article/view/155

Mcnamee, S. \& Gergen, K. J. (Orgs.) (1998). A terapia como construção social. Porto Alegre: Artes Médicas. Minuchin, S. (1982). Família, funcionamento e tratamento. Porto Alegre: Artes Médicas. 
Morin, E. (1982). Ciência com consciência. Lisboa: Publicações Europa-América.

Oliveira, D., Siqueira, A. C., Dell'Aglio, D. D., \& Lopes, R. C. S. (2008). Impacto das configurações familiares no desenvolvimento de crianças e adolescentes: uma revisão da produção científica. Interação em Psicologia, 12(1), 87-98.

Pasley, K. \& Garneau, C. (2016). Recasamento e família recasada. In $\mathrm{F}$. Walsh (Org.), Processos normativos da família: diversidade e complexidade (pp. 149-171). Porto Alegre: Artmed.

Rocha, A. Pr R. R. (2015). O padrasto na família recasada: uma análise da produção acadêmica brasileira. Dissertação de Mestrado, Programa de Pós-graduação em Psicologia, Universidade Federal de Alagoas. Maceió. Recuperado de http://www.ufal.edu. br/unidadeacademica/ip/pos-graduacao/mestrado-em-psicologia/ dissertacoes/2015/adriana-pitta-ramos-rocha-o-padastro-na-familia-recasada-uma-analise-da-producao-academica-brasileira.

Saccu, C. \& Montinari, G. (1995). As crianças, pequenos Ulisses entre Cila e Caribde. In M. Andolfi, C. Angelo, \& C. Saccu (Orgs.), O casal em crise ( $3^{a}$ ed., pp.183-192) São Paulo: Summus.

Saraiva, C. A. (2013) Ser padrasto em famílias recompostas: os desafios da pluriparentalidade. Dissertação de Mestrado, Programa de Pós-graduação em Psicologia, Pontifícia Universidade Católica do Rio de Janeiro, RJ. Recuperado de http://www2.dbd. puc-rio.br/pergamum/tesesabertas/1111664_2013_completo.pdf.

Saraiva, C. A.s Levy, L., \& Magalhães, A. S. (2014). O lugar do padrasto em famílias recompostas. Barbarói, 41, 82-99.
Serafim, A. Pr, Saffi, Fr, Achá, M. Fr F., \& Barros, D. M. (2011). Dados demográficos, psicológicos e comportamentais de crianças e adolescentes vítimas de abuso sexual. Revista de Psiquiatria Clínica, 38(4), 143-147.

Silva, I. A. G. (2013). A nova Lei do Divórcio e a extinção tácita da separação judicial. In Âmbito Jurídico, XVI, 112. Recuperado de http://ambito-juridico.com. $\mathrm{br} / \mathrm{site} /$ ?n_link=revista_artigos_ leitura\&artigo_id=13276\&revista_ caderno $=14$

Silva, P. 0. M., Trindade, Z. A.s \& Silva, A. (2012). As representações sociais de conjugalidade entre casais recasados. Estudos de Psicologia, 17(3), 435443. https://dx.doi.org/10.1590/ S1413-294X2012000300012

Soares, L. C. E. C. (2009). "No fogo cruzado": desafios e vivências de pais e mães recasados. Dissertação de Mestrado, Programa de Pós-graduação em Psicologia Social, Universidade do Estado do Rio de Janeiro, RJ. Recuperado de http://livros01. livrosgratis.com.br/cp079533.pdf

Soares, L. C. E. C. (2012). "Você não é meu pai!": atribuições de padrastos e madrastas em famílias recasadas após separação conjugal. Estudos e Pesquisas em Psicologia (UERJ), 12(1), 319-326.

Souza, R. M. (2000). Depois que mamãe e papai se separaram: um relato dos filhos. Psicologia: Teoria e Pesquisa, 16(3), 203-211.

Souza, R. M. \& Ramires, V. R. (2006). Amor, casamento, família, divórcio... e depois, segundo as crianças. São Paulo: Summus.

Travis, S. (2003) Construções familiares: um estudo sobre a clínica do recasamento. Tese de Doutorado, Programa de Pós-graduação em Psicologia Clínica, Pontifícia 
Universidade Católica do Rio de Janeiro, RJ.

Trindade, L. C., Linhares, S. M. G. M., Vanrell, J., Godoy, D., Martins, J. C. A., \& Barbas, S. M. A. N. (2014). Violência sexual infantil e vulnerabilidade. Revista da Associação Médica Brasileira, 60(1), 70-74.

Valentim de Sousa, D. H. A., \& Dias, C. M. S. B. (2014). Recasamento: percepções e vivências dos filhos do primeiro casamento. Estudos de Psicologia (Campinas), 31(2), 191-201. https://dx.doi.org/10.1590/0103-166X2014000200005

Vasconcellos, M. J. E. (2010). Pensamento sistêmico: o novo paradigma da ciência ( $9^{a}$ ed.). Campinas, SP: Papirus.

Wagner, A. (2002). Possibilidades e potencialidades da família: a construção de novos arranjos a partir do recasamento. In Família em cena: traumas, dramas e transformações (pp. 23-38). Petrópolis, RJ: Vozes, Wagner, An, Ribeiro, L. S., Arteche, A. X. \& Bornholdt, E. A. (1999). Configuração familiar e o bem-estar psicológico dos adolescentes. Psicologia: Reflexão e Crítica, 12(1), 147-156.

Wallerstein, J. \& Kelly, J. (1998). Sobrevivendo à separação: como pais e filhos lidam com o divórcio. Porto Alegre: Artmed.

Wallerstein, Ja, Lewis, J., \& Blakeslee, S. (2002). Filhos do divórcio. São Paulo: Edições Loyola.
MARCELO RICHAR ARUA PIOVANOTTI

Psicólogo e mestre em Psicologia pela Universidade Federal de Santa Catarina. Especialista em Terapia Relacional Sistêmica pelo Familiare Instituto Sistêmico de Florianópolis. Psicólogo clínico do Núcleo Ampliado de Saúde da Família e Atenção Básica da Secretaria Municipal de Saúde de Florianópolis. Florianópolis, SC, Brasil.

E-mail: piovanotti@gmail.com

\section{DENISE DUQUE}

Psicóloga especialista clínica. Terapeuta individual, de casais e famílias. Coordenadora do Familiare Instituto Sistêmico de Florianópolis, SC, Brasil. E-mail: denisefd11@gmail.com 